\title{
The occipital artery for posterior circulation bypass: microsurgical anatomy
}

\author{
ÖZkan Ateş, M.D., ${ }^{1}$ Azam S. Ahmed, M.D., ${ }^{1,2}$ DaVid Niemann, M.D., ${ }^{1,2}$ \\ AND MUSTAFa K. BaŞKAYA, M.D. ${ }^{1,2}$ \\ ${ }^{1}$ Department of Neurological Surgery, University of Wisconsin; and ${ }^{2}$ Veterans Administration \\ Hospital, Madison, Wisconsin
}

\begin{abstract}
Object. The microsurgical anatomy of the occipital artery (OA) was studied to describe the diameter, length, and course of this vessel as it pertains to revascularization procedures of the posterior cerebral circulation.

Methods. The authors studied 12 OAs in 6 cadaveric heads that had been injected with colored latex. They evaluated the OA's ability to serve as a conduit for extracranial-intracranial (EC-IC) bypass in the posterior circulation. They measured the length of the $\mathrm{OA}$ and its diameter at common sites of anastomosis and compared these values with the diameters of the recipient vessels $\left(\mathrm{V}_{3}\right.$ and $\mathrm{V}_{4}$ segments of the vertebral artery, caudal loop of the posterior inferior cerebellar artery [PICA], and anterior inferior cerebellar artery [AICA]).

Results. The mean thickness of the suboccipital segment of the OA was found to be $1.9 \mathrm{~mm}$. The mean distance of the OA from the external occipital protuberance was found to be $45 \mathrm{~mm}$. The mean length of the suboccipital segment of the OA was $79.3 \mathrm{~mm}$. The mean thickness of the largest trunk of the $\mathrm{V}_{3}$ segment, the $\mathrm{V}_{4}$ segment, the caudal loop of the PICA, and the AICA were $3.3 \mathrm{~mm}, 3.1 \mathrm{~mm}, 1.2 \mathrm{~mm}$, and $1 \mathrm{~mm}$, respectively.

Conclusions. The length, diameter, and flow accomodated by the OA make it an ideal choice as a conduit for posterior circulation bypass. The bypass from the OA to the caudal loop of the PICA demonstrates the least difference in vessel diameter, and is therefore best suited for EC-IC bypass procedures in the posterior circulation.
\end{abstract}

(DOI: $10.3171 /$ FOC/2008/24/2/E9)

\author{
Key WoRds - bypass - microsurgical anatomy • occipital artery • \\ posterior circulation • vertebral artery
}

$\mathrm{S}$ INCE the first successful report of EC-IC bypass surgery by Yaşargil et al., ${ }^{10}$ cerebral revascularization has been an important procedure for the treatment of ischemic neurological disease, skull base tumors involving the VA and its branches, and complex and giant intracranial aneurysms..$^{2-4,9}$ In current surgical practices, the superficial temporal artery, saphenous vein, radial artery, and OA are used as donor grafts for cerebral revascularization. ${ }^{2-5,9}$ The OA is a particularly appealing choice for posterior circulation bypass procedures due to its proximity to the target recipient vessels. In this study, we investigated the detailed microsurgical anatomy of the $\mathrm{OA}$ as it pertains to posterior circulation bypass surgery.

\section{Materials and Methods}

Six adult cadaveric heads with 12 OAs were injected with colored latex. With the heads in the prone position, the

Abbreviations used in this paper: AICA = anterior inferior cerebellar artery; EC-IC = extracranial-intracranial; OA = occipital artery; PICA = posterior inferior cerebellar artery; $\mathrm{SNL}=$ superior nuchal line; $\mathrm{VA}=$ vertebral artery. suboccipital region was exposed through a hockey stickshaped scalp flap. The incision began in the midline, $\sim 8$ $\mathrm{cm}$ below the external occipital protuberance, and was directed upward to just above the external occipital protuberance. The incision then turned laterally ending immediately superior to the mastoid process. Finally, the incision curved inferiorly $\sim 1 \mathrm{~cm}$ to end immediately inferior to the mastoid process.

The segments of the OA have been well delineated by Alvernia et al. ${ }^{1}$ After dissecting through the subcutaneous tissues, we identified the suboccipital segment of the OA, extending from the occipital groove to the SNL, and dissected it circumferentially (Fig. 1). After the subperiosteal muscle dissection, a suboccipital craniectomy and C-1 laminectomy were performed. We identified the $\mathrm{V}_{3}$ segment of the VA, which exits the transverse foramen of the axis and curves posteriorly and medially in a groove on the upper surface of the atlas, the sulcus arteriosus, and enters the foramen magnum. The dura was then opened, and the $\mathrm{V}_{4}$ segment (which pierces the dura mater and immediately enters the subarachnoid space), PICA, and AICA were identified. The diameters of the recipient vessels (the $\mathrm{V}_{3}$ and $\mathrm{V}_{4}$ segments, the PICA, and the AICA) were measured. 
TABLE 1

Length of $O A$ required for various bypass procedures

\begin{tabular}{ccc}
\hline \hline \multirow{2}{*}{ Recipient Vessel } & \multicolumn{2}{c}{ Length of OA Required } \\
\cline { 2 - 3 } & Mean (mm) & Range (mm) \\
\hline $\mathrm{V}_{3}$ segment & 40 & $38-43$ \\
$\mathrm{~V}_{4}$ segment & 50 & $48-52$ \\
caudal loop of PICA & 58 & $54-60$ \\
AICA & 59 & $55-62$ \\
\hline
\end{tabular}

The OA was mobilized and transferred to the anastomotic areas at the level of the recipient vessels. The diameter of the OA at these levels was measured. The ends of the suboccipital segment of the OA, $\mathrm{V}_{3}$ (Fig. 3) and $\mathrm{V}_{4}$ (Fig. 4) segments, the caudal loop of the PICA (Figs. 2 and 5), and the AICA were prepared for bypass surgery. The anastomosis was performed using 8-0 and 10-0 nylon sutures and standard microsurgical techniques.

\section{Results}

In all cases, we were able to successfully identify and mobilize the suboccipital segment of the OA and anastomose it with the recipient vessel. The mean diameter of the ends of the suboccipital segment of the OA at the level of the SNL was $1.9 \mathrm{~mm}$. The length of the suboccipital segment of the OA lateral to the external occipital protuberance measured 3.5-5.2 $\mathrm{mm}$ (mean $4.5 \mathrm{~mm}$ ). The mean length of the suboccipital segment of the OA was $79.3 \mathrm{~mm}$ (range $75-85 \mathrm{~mm}$ ). The mean lengths of the OA grafts required for $\mathrm{V}_{3}$ segment-OA, $\mathrm{V}_{4}$ segment-OA, caudal loop of PICA-OA, and AICA-OA bypass surgeries were found to be $40 \mathrm{~mm}, 50 \mathrm{~mm}, 58 \mathrm{~mm}$, and $59 \mathrm{~mm}$, respectively (Table 1). The mean diameters of the $\mathrm{V}_{3}$ segment, the $\mathrm{V}_{4}$ segment, the PICA, and the AICA were found to be 3.3 $\mathrm{mm}, 3.1 \mathrm{~mm}, 1.2 \mathrm{~mm}$, and $1 \mathrm{~mm}$, respectively (Table 2).

\section{Discussion}

Posterior circulation bypass surgery has been used to treat many cranial pathological conditions such as ischemic neurological disease, skull base tumors involving the VA and its branches, and complex and giant intracranial aneurysms. ${ }^{2-4,9}$ Kawashima et al. ${ }^{5}$ commented on the challenges in tackling posterior when compared with anterior cerebral revascularization procedures. For posterior circulation bypass surgery, the surgical indications are less well defined

TABLE 2

Diameter of measured arteries and segments

\begin{tabular}{ccc}
\hline \hline Artery or Segment & Mean $(\mathrm{mm})$ & Range $(\mathrm{mm})$ \\
\hline suboccipital segment of OA & 1.9 & $1.6-2.2$ \\
$\mathrm{~V}_{3}$ segment of VA (extradural) & 3.3 & $2.1-4.2$ \\
$\mathrm{~V}_{4}$ segment of VA (intradural) & 3.1 & $2.1-4$ \\
caudal loop of PICA & 1.2 & $0.9-1.4$ \\
AICA & 1 & $0.8-1.2$ \\
\hline
\end{tabular}

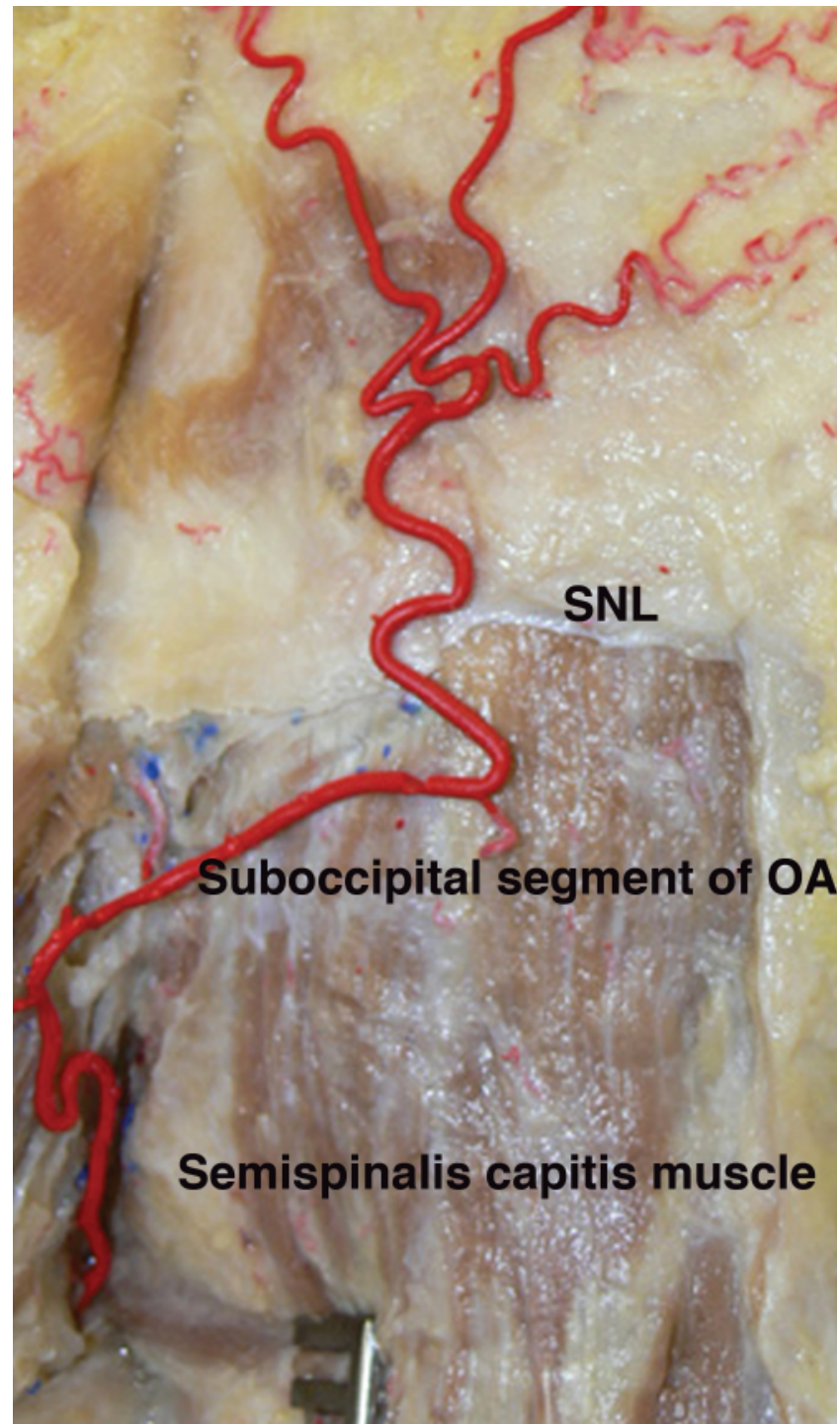

FIG. 1. Photograph of a cadaveric specimen demonstrating the course of the OA after initial exposure. Note the near-horizontal course of the suboccipital segment of the OA.

due to a number of factors. The patient's symptoms are often related to critical areas, including the brainstem, that contain recipient vessels with smaller diameters. Also, performing the anastomosis in the deep and narrow operative corridor near the brainstem and cranial nerves is arduous. Nevertheless, in many situations, the posterior circulation bypass procedure remains an important tool in the armamentarium of the neurovascular surgeon.

Several vascular grafts are avaliable for posterior circulation bypass surgery. These vascular grafts include the superficial temporal artery, the radial artery, the saphenous vein, ${ }^{2-5,9}$ and the OA. ${ }^{2,3,6-8}$ In this study we used the suboccipital segment of the OA as the donor vessel and the $\mathrm{V}_{3}$ and $\mathrm{V}_{4}$ segments of the VA, the PICA, and the AICA as the recipient vessels. The selection of an anastomotic recipient site is related to the patient's symptoms, collateral circulation, and the site of the lesion. 


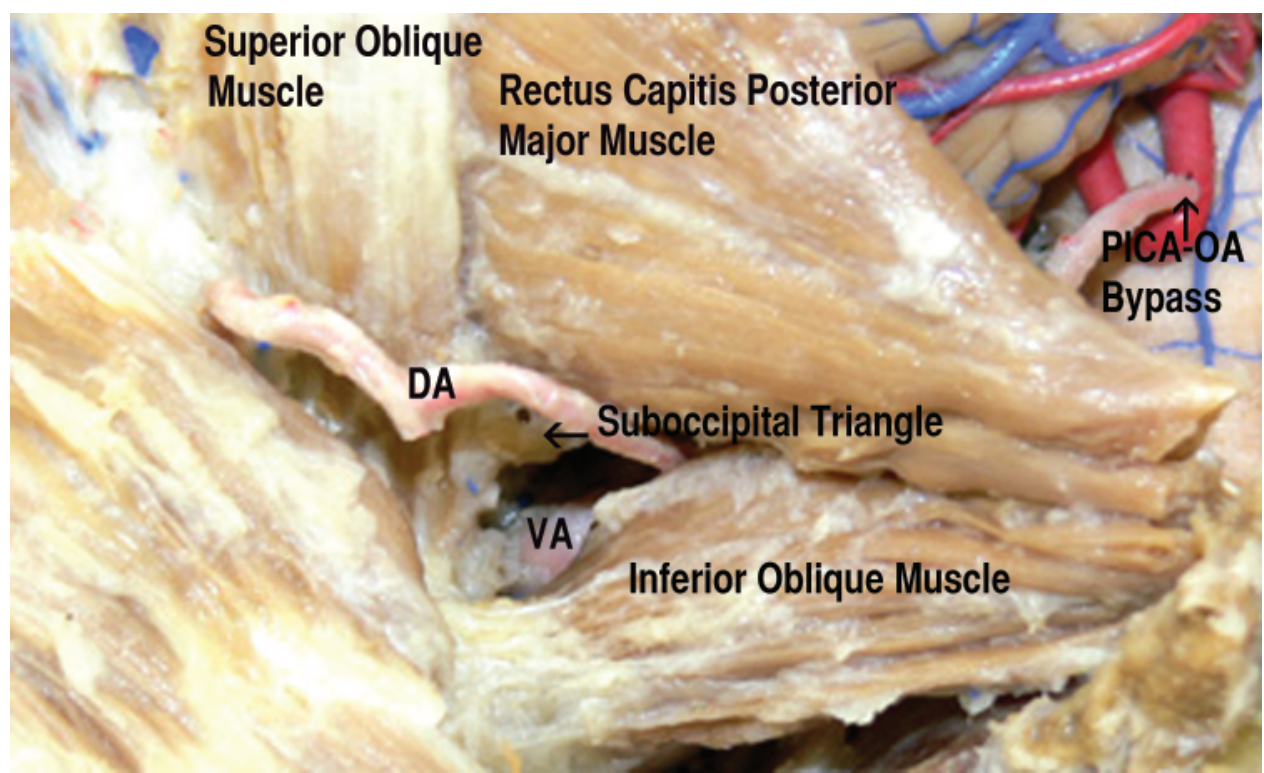

FIG. 2. Photograph demonstrating the course of the OA in the suboccipital triangle.

The OA as a donor graft has certain advantages and disadvantages when compared with the other potential donor vascular grafts.

The diameter of the OA at the level of the SNL is variously reported in the literature as being between 1.4 and 2 mm. ${ }^{1,5}$ In this study, we determined the suboccipital OA diameter to be $1.9 \mathrm{~mm}$, a size that closely approximates that of the PICA and AICA. In a study by Kawashima et al., 5 the length of suboccipital segment of the OA was found to be $81 \mathrm{~mm}$. In the present study, the mean length of this segment was $79.3 \mathrm{~mm}$. This length is adequate for posterior circulation bypass procedures where the $\mathrm{V}_{3}$ and $\mathrm{V}_{4}$ segments, the AICA, and the PICA are the recipients. The accessibility of the suboccipital OA is an ideal choice as it is encountered during the dissection when performing a suboccipital craniotomy. Therefore, the bypass procedure can be accomplished through 1 skin incision. Potential disadvantages of the use of the OA include graft dissection due to the tortuous route and deep location in the occipital muscle. ${ }^{5}$

\section{Types of Posterior Circulation Bypasses}

Occipital Artery- $V_{3}$ Segment. The mean diameter of the $\mathrm{V}_{3}$ segment was determined to be $3.3 \mathrm{~mm}$, which is significantly larger than the $\mathrm{OA}$ at this level. Therefore, if the clinical scenario calls for a high-flow bypass, the diameter of the OA may not provide adequate flow. If an anastomosis is performed at this level, some portion of the bypassed flow may be lost to muscular branches of the VA. However,

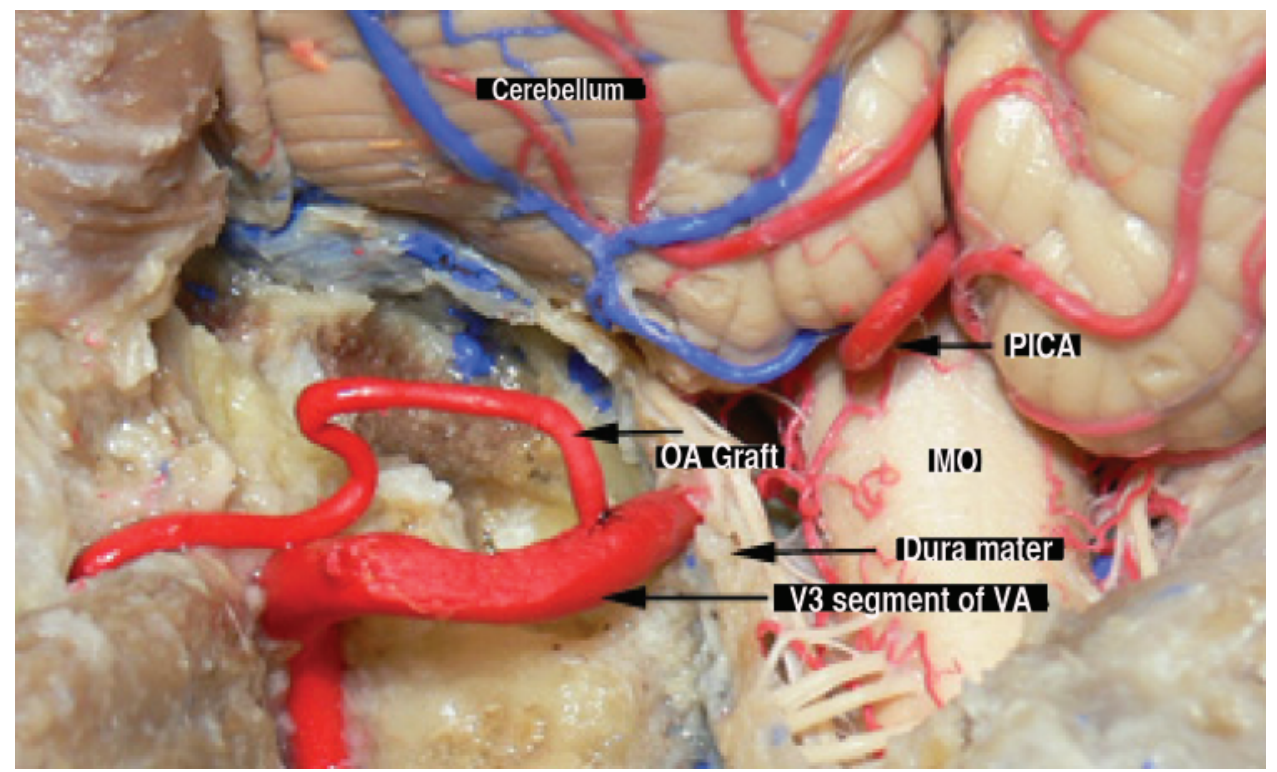

FIG. 3. Photograph showing the $\mathrm{OA}-\mathrm{V}_{3}$ segment bypass. $\mathrm{MO}=$ medulla oblongata. 
Ö. Ateş et al.

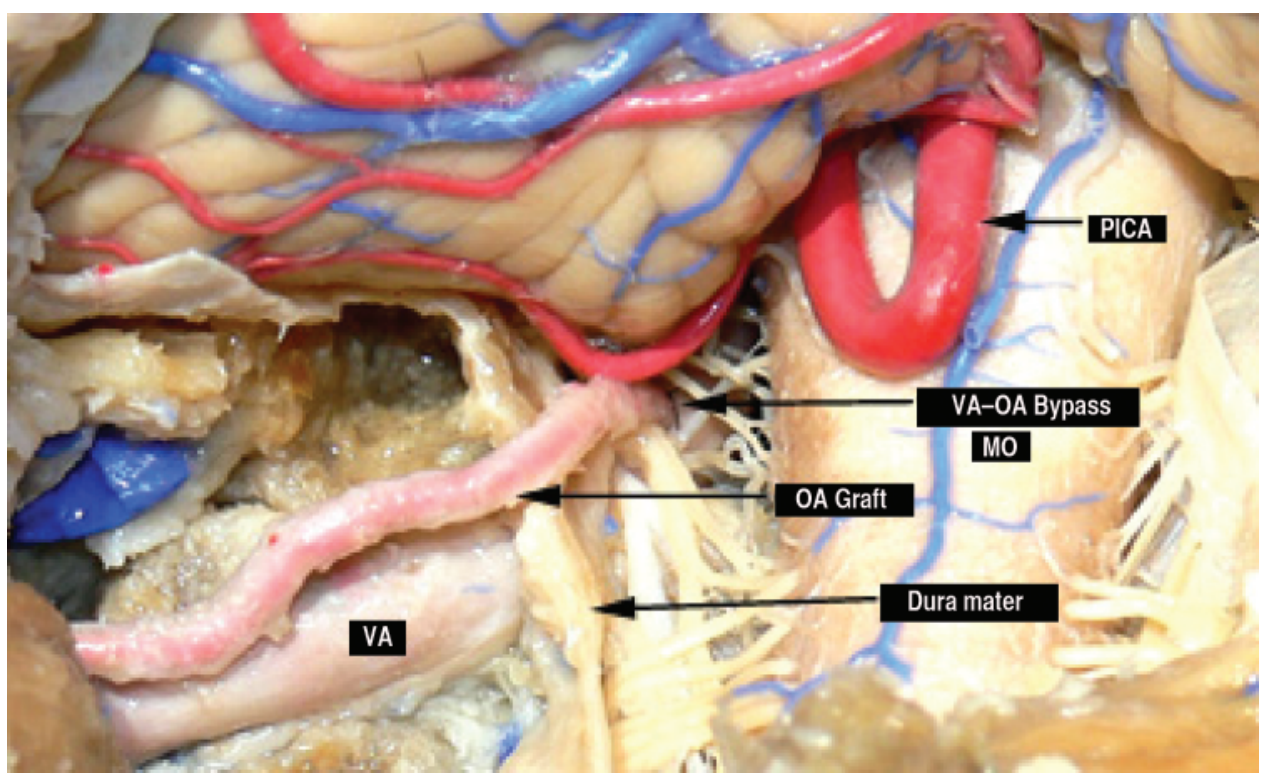

FIG. 4. Photograph illustrating the $\mathrm{OA}-\mathrm{V}_{4}$ segment bypass.

the $\mathrm{V}_{3}$ segment is quite superficial and extradural; this location mitigates the risks of cerebrospinal fluid leak and the morbidity of potential neurovascular injury (Fig. 3).

Occipital Artery- $V_{4}$ Segment. While the diameter of the $\mathrm{V}_{4}$ segment is less than that of the $\mathrm{V}_{3}$ segment, it remains significantly larger than the OA at this level. Furthermore, the intradural location and proximity of the $\mathrm{V}_{4}$ segment to the brainstem and lower cranial nerve may increase the surgical difficulty (Fig. 4).

Occipital Artery-PICA. The diameters of the OA and caudal loop of the PICA are well matched, and the superficial location with separation from the caudal cranial nerves makes this recipient an ideal candidate (Figs. 2 and 5).

Occipital Artery-AICA. At the level of the distal AICA, the diameter of the OA is significantly smaller. Furthermore, the operative field is deep and the surgical corridor is narrow. Lastly, cerebellar retraction is nearly always necessary to gain access to the distal AICA. These characteristics provide for a technically challenging procedure.

\section{Conclusions}

While posterior circulation EC-IC bypass surgery remains technically challenging, these procedures continue to play a role in various clinical scenarios. The diameter and length of the suboccipital segment of the $\mathrm{OA}$ is adequate and bypass procedures are feasible where the $\mathrm{V}_{3}$ and $\mathrm{V}_{4}$ segments, the caudal loop of the PICA, and the distal AICA can be used as recipient vessels. Nevertheless, the caudal

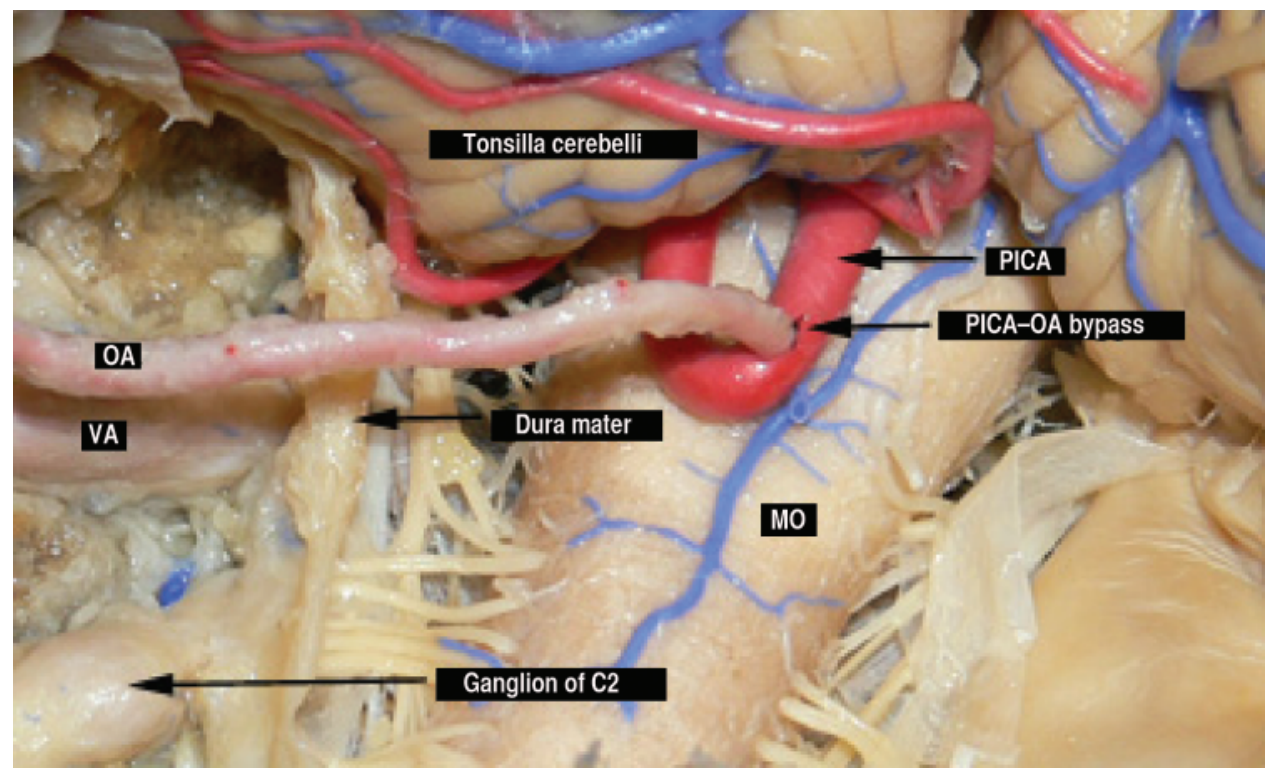

FIG. 5. Photograph of the OA-PICA bypass. 
loop of PICA-OA bypass procedure remains the best option for posterior circulation bypass surgery as a result of the minor difference in diameter and the proximity of these 2 vessels.

\section{References}

1. Alvernia JE, Fraser K, Lanzino G: The occipital artery: a microanatomical study. Neurosurgery 58 (1 Suppl):114-122, 2006

2. Ausman JI, Diaz FG, Vacca DF, Sadasavin B: Superficial temporal and occipital bypass pedicles to superior, anterior inferior, and posterior inferior cerebellar arteries for vertebrobasilar insufficiency. J Neurosurg 72:554-558, 1990

3. Ausman JI, Lee MC, Klassen AC, Seljeskog EL, Chou SN: Stroke: what's new? Cerebral revascularization. Minn Med 59: 223-227, 1976

4. Friedman JA, Piepgras DG: Current neurosurgical indications for saphenous vein graft bypass. Neurosurg Focus 14(3):E1, 2003

5. Kawashima M, Rhoton AL Jr, Tanriover N, Ulm AJ, Yasuda A, Fujii K: Microsurgical anatomy of cerebral revascularization. Part II: posterior circulation. J Neurosurg 102:132-147, 2005
6. Khodadad G: Occipital artery-posterior inferior cerebellar artery anastomosis. Surg Neurol 5:225-227, 1976

7. Lewis SB, Chang DJ, Peace DA, Lafrentz PJ, Day AL: Distal posterior inferior cerebellar artery aneurysms: clinical features and management. J Neurosurg 97:756-766, 2002

8. Roski RA, Spetzler RF, Hopkins LN: Occipital artery to posterior inferior cerebellar artery bypass for vertebrobasilar ischemia. Neurosurgery 10:44-49, 1982

9. Sekhar LN, Kalakovanda C: Cerebral revascularization for aneurysms and tumors. Neurosurgery 50:321-331, 2002

10. Yaşargil MG, Krayenbuhl HA, Jacobson JH II: Microneurosurgical arterial reconstruction. Surgery 67:221-233, 1970

Manuscript submitted November 15, 2007.

Accepted December 11, 2007.

Address correspondence to: Mustafa K. Başkaya, M.D., Department of Neurological Surgery, Clinical Science Center-K4/ 828, 600 Highland Avenue, Madison, Wisconsin 53792. email: m.baskaya@neurosurg.wisc.edu. 